
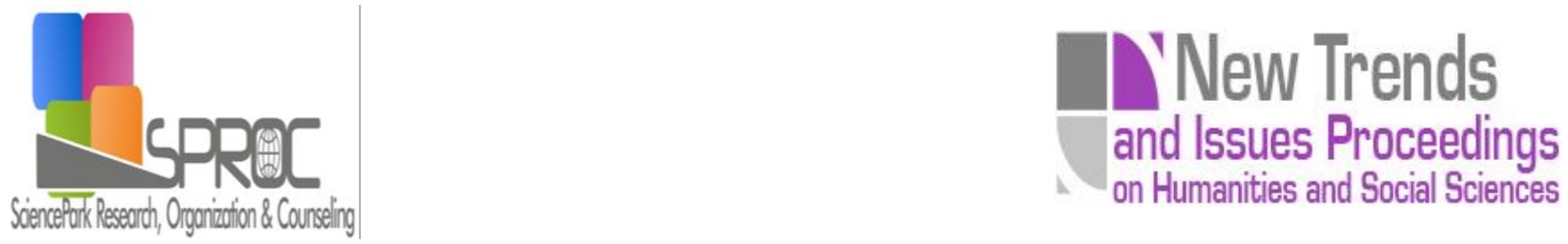

\title{
Leisure time activities of students at teaching faculties from three countries
}

\author{
Sivevska Despina ${ }^{\text {* }}$ \\ Popeska Biljana ${ }^{b}$ \\ Gregorc Jerac \\ Ignatov Georgid
}

Suggested Citation:

Abstract 
1. Introduction 
2. Methodology 
3. Results and discussion 
Table 1. Differences between students from three countries upon manners of spending their leisure time 
Table 2. Differences between students related the frequency of attendance of cinema, Theatre, concerts, discotheques, art exhibitions, galleries and sport events. 


\subsection{The role of University in organization of student's leisure time}


Table 3. Differences between students based on their attidudes toward the role of University in organization of their leisure time

4. Conclusion 


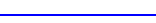


References

O

o

O 


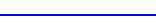

